\title{
A Genealogy Ontology Containing Turkish Kinship Terms for Traditional Families
}

\author{
Mehmet Milli \\ Bolu Abant Izzet Baysal University, Faculty of Engineering, Bolu, Turkey \\ E-mail: mehmetmilli@ibu.edu.tr
}

\begin{abstract}
Today, with the innovations brought by technology, many information, official documents, correspondence, and evaluation data kept in archives have been transferred to digital environment. One of the areas where the digitalization process has started and continues rapidly is population and registry information. However, the existing systems are sometimes insufficient to present the log information clearly. Existing systems used in relevant government institutions and libraries can only present kinship ties in a hierarchical structure due to the lack of necessary infrastructure resources. The family tree created is insufficient to establish parallel relationships. However, it is obvious that in most judicial and institutional cases, it will shed light on the current situation in parallel kinship relations. In addition, existing genealogies are insufficient to reveal semantic patterns between the concepts of family, person, place, time, and event while listing kinship relations. In addition to all these, the existence of cultural differences between nations and the expression of kinship relations with different terms require the definition of a common family tree. In this study, semantic web technologies, ontologies, and related data, which have been widely used in many fields in recent years, are structured to provide a clearer conceptualization of kinship relations. The study also discusses the alignment and reusability of the developed genealogical ontology with upper-level ontologies so that it can be used more broadly.
\end{abstract}

Keywords: Genealogical Ontology, Semantic Web Technologies, Linked Data, Protégé, Ontology Methodologies

DOI: $10.7176 / J S T R / 7-10-10$

\section{Geleneksel Aileler İçin Türkçe Akrabalık Terimlerini İçeren Bir Soybilim Ontolojisi}

\begin{abstract}
Özet
Günümüzde teknolojinin getirdiği yenilikler ile beraber arşivlerde tutulan birçok bilgi, resmi belge ve yazışma ve değerlendirme verileri dijital ortamlara aktarıldı. Dijitalleşme süreci başlayan ve hızlı bir şekilde devam eden alanlardan biriside nüfus ve kütük bilgileridir. Fakat kütük bilgilerinin net bir şekilde ortaya koyulması için mevcut sistemler bazen yetersiz kalmaktadır. İlgili devlet kurumlarında ve kütüphanelerde kullanılan mevcut sistemler akrabalık bağlarını gerekli altyapı kaynaklarının olmaması sebebiyle ancak hiyerarşik bir yapıda sunabilirler. Oluşturulan soyağacı paralel ilişkiler kurmada yetersiz kalmaktadır. Hâlbuki çoğu adli ve kurumsal olayda paralel akrabalık ilişkilerinin de, mevcut duruma ışık tutacağı aşikârdır. Ayrıca hali hazırda mevcut soy kütükleri akrabalık ilişkilerini listelerken aile, kişi, yer, zaman ve olay kavramları arasında anlamsal örüntüleri ortaya koymakta yetersiz kalmaktadır. Tüm bunların yanında milletler arası kültürel farklılıkların olması, akraba ilişkilerinin farklı terimler ile ifade edilmesi ortak bir soy ağacı tanımlamalarını gerektirmektedir. Bu çalışmada son yıllarda birçok alanda yaygın olarak kullanılmaya başlayan semantik web teknolojileri, ontolojiler ve bağlı veriler akrabalık ilişkilerinin daha açık kavramsallaştırılmasını sağlayacak şekilde yapılandırılmıştır. Çalışma ayrıca geliştirilen soybilim ontolojisinin daha geniş kapsamda kullanılabilmesi için upper seviye ontolojiler ile hizalanmasını ve tekrar kullanılabilirliğini de tartışmaktadır.
\end{abstract}

89 | P a g e

www.iiste.org 


\section{Giriş}

Son çeyrek asırdır özellikle teknolojik aletlerin altyapılarının gelişmesi ve cihazların çeşitlenmesinin sağladığı avantajlar ile dijitalleşmeye çağına girilmiştir ve kısa zamanda büyük bir ivme kazanılmıştır (Milli, 2021).Çok yakın bir geçmişte arşivlerde, depolarda, fiziksel dosyalar ile tutulan tapu, nüfus bilgileri, banka işlem kayıtları, eğitim dökümanları gibi resmi kayıtlar artık günümüz çağında bilgisayar ortamlarında saklanmaya başlamıştır. Bireylerin özel hayatını yakından ilgilendiren bu resmi evrakları dijital ortamlarda saklamanın bir çok olumsuz yönü olabilir. Bunların en başında güvenlik ve gizlilik sorunları gelmektedir. Bununla beraber dijital sistemlerinin çökmesi sonucu verilerin kaybedilmesi, hizmetlerin kesintiye uğraması, alt yapı kurulum maliyetlerinin yüksek olması da dijitalleşmenin dezavantajları arasında yer almaktadır (Kazan, 2017).

Fakat dijitalleşmenin getirdiği son derece önemli bazı zaafiyetlerin ve zorlukların olması kurumların ve bireylerin buna ayak uydumasına engel teşkil etmemektedir. Şüphesiz ki bununda en büyük sebebi dijitalleşmenin getirdiği avantajların, dez avntajlarından daha fazla olması gösterilebilir. Dijitalleşmenin getirdiği avantajları operasyonel verimliliği artıırılması, hızlı aksiyom alınabilmesi, analiz yapabilme yeteneklerinin geliştirmesi, kurumsal hafizayı geliştirmesi, sürdürebililiği sağlaması ve şirket içi departman ve kişi bazlı değerlendirmenin rahtalıkla yapılabilmesi olarak sıralayabiliriz. Ayrıca, dijitalleşme var olan iş kolarına farklı ve yeni alanlar eklemiştir. Bunun yanında dijitalleşme mevcut iş süreçleri için şirket kaynaklarını ve dijital teknolojiler ile harmanlayarak farklı müşteri deneyimleri oluşturmaktadır (Accenture, 2015). Önerilen çalışmada, soyağacı verilerinin daha anlamlı temsil edilmesi ve yazılım ajanları tarafindan da yorumlanabilmesi için ortak bir ontoloji çerçevesi yaratılmıştır.

Literatürde ontolojisinin birçok tanımlaması olmasına karşın en yaygın kabul gören tanımı Gruber'in 1990'lı yılların ortasında yaptığı tanımdır. Gruber'e göre ontoloji kavramsallaştırmanın açık gösterimidir (Gruber, 1993). Bilginin makineler tarafindan da yorumlanabimesi için kavramsallaştırılması, yeniden kullanılabilmesi ve ortak amaca yönelik uygulamalar arasında paylaşımın desteklenmesi için bilginin temsil edildiği asgari kelime dağarcığının tanımlanması önemlidir (Gruber, 1995). Başka bir deyişle ontoloji makinelere insanların dilini öğretmektense, içerikleri onların anlayabileceği formatta oluşturmak için bir yoldur (Maedche \& Staab, 2000). Ontoloji, soyağacı gibi belirli bir etki alanı için ilgili kavramları, kodlanmış bilginin makineler tarafindan işlenebilir ve anlaşılabilir olduğu makine tarafindan okunabilir bir formatta kodladığ güçlü bir dildir (Tan \& Hashim, 2019). Bu çalışmada bir çok kamu kurumunda dijatelleşme süreci başlamış olan soyağacı bilgilerinin semantic web ve linked data teknolojileri ile harmanlanarak daha anlamlı ve etkin temsil edilmesi için bir ontoloji çerçevesi önerilmektedir.

İlgili devlet kurumlarında, ve kütüphanelerde kullanılan mevcut sistemler akrabalık bağlarını gerekli altyapı kaynaklarının olmaması sebebiyle ancak hiyerarşik bir yapıda sunabilirler. Bu yetersizliklerin en başında ise mevcut sistemlerin oluşturduğu soyağaçlarının pararlel iliş̧kiler kurmada yetersiz kalması gelmektedir. Halbuki çoğu adli ve kurumsal olayda paralel akrabalık ilişkilerininde mevcut duruma ışık tutacağı aşikardır. Ayrıca hali hazırda mevcut soy kütükleri akrabalık ilişkilerini listelerken aile, kişi, yer, zaman ve olay kavramları arasında anlamsal örüntüleri ortaya koymakta yetersiz kalmaktadır. Bu çalışmada son yıllarda birçok alanda yaygın olarak kullanılmaya başlayan semantik web teknolojileir, ontolojiler ve bağlı veriler akrabalık ilişkilerinin daha açık kavramsallaştırılmasını sağlayacak şekilde yapılandırılmıştır. Bu teknolojilerin mevcut kütük sistemlerinin bazı sorunlarına çözüm getireceği düşünülmektedir. Bu makalenin geri kalanı aşağıdaki gibi organiz edilmiştir.

Önerilen makalenin ilk bölümünde mevcut soyağacı bilgi sistemlerinin eksiklikleri ve bu çalışmanın bazı eksikliklere hangi teknolojileri kulanarak, nasıl çözüm getireceği tartışılmıştır. İkinci kısımda literatürde benzer çalışma çok olmasada daha önce bu konu hakkında yapılmış yayınlara yer verilecektir. Çalışmada kullanılan yöntem ve materyaller bölüm 3 'te açıklanacaktır. Bu bölümde ontolojinin hangi metodaloji ile kurulduğu, hangi ontoloji araçlarının kullanıldığı detaylandırılacaktır. $\mathrm{Bu}$ makalenin beşinci ve son bölümünde çalışma sonunda elde edilen sonuçlar yorumlanarak mevcut sistemlere getireceği faydalar tartışlacaktır. Yine son bölümde önerilen çalışmanın devamı olabilecek gelecek çalışmalar tartışılacak ve bir karara bağlanacaktır.

\section{Literatür taraması}

Daha önceden çalışılmış bazı soybilimsel ontolojiler olmasına rağmen (Tan \& Hashim, 2019; Xia, C.J., Liu, W., Zhang, L. and Zhu, 2014) bu ontolojiler akıl yürütme, mantıksal çıkarımları, hiyerarjik yapıları ve tutarlılıkları bakımından genişletilebilir ve geliştirilebilir. Ontolojiler her ne kadar bir alandaki kavramların ortak kullanımına eğilimli olsalarda soybilim alanında milletler arası kültürel

$90 \mid \mathrm{P}$ a g e

www.iiste.org 
farklılıkların getirmiş olduğu terimsel farklılıklardan dolayı bu pek mümkün olmayabilir. Avrupa ve Amerika toplumlarında geniş aile fertlerinin birçoğu genelde tek bir terim ile ifade edilebilirken, Türkiye gibi daha geleneksel toplumlarda aile fertlerinin herbiri için farklı terimler mevcut olabilmektedir. Örneğin batı toplumlarında anne ve babanın erkek kardeşlerinin herbirine genel olarak 'uncle' denmektedir. Fakat daha geleneksel toplumlarda annenin erkek kardeşi farklı, babanın erkek kardeşi farklı isimlerindirilir. Örneğin Türkler babanın erkek kardeşine 'amca' derken, annenin erkek kardeşine 'dayı' terimlerinin oldukça yaygın bir şekilde kullanırlar.

Tüm bu farklılıkların yanında geleneksel toplumlar evlilik bağı ile oluşan akrabalıklarda bile aileye yeni katılan her bir fert için farklı bir terim kullanılacak kadar geniş aile terminolojisi mevcuttur. Geleneksel toplumlarda aileye yeni katılan bireylere kayınpeder, kaynana, bacanak, baldız, elti kayın birader gibi örnekler verilebilir. Bu bağlamda düşünüldüğünde bu çalşma Türkçe terimleri içeren kapsamlı ilk soybilimsel ontolojidir. Fakat her kültür için farklı bir ontoloji çerçevesi tasarlanması semantik web teknolojileri mantığına ters düşmektedir. Bu durum ancak belirli bir alanda belli bir kültür için oluşturulan ontoloji çerçevesinin, literatürde kullanılan Descriptive Ontology for Linguistic and Cognitive Engineering (DOLCE) (Gangemi, Guarino, Masolo, Oltramari, \& Schneider, 2002), Suggested Upper Merged Ontology (SUMO) (Kuraoka \& Batres, 2003) ve Proto Ontology (PROTON) (Terziev, Kiryakov, \& Manov, 2003) gibi upper seviye ontolojiler ile hizalanması ile çözüme kavuşabilir. Böylelikle farklı dillerde farklı milletlerin kültürlerinden kaynaklanan terim kargaşası bir nebze olsun engellenmiş olur.

\section{Materyal ve Yöntem}

$\mathrm{Bu}$ çalışma nüfus bilgilerini içeren kavramların daha somut anlaşıııasını sağlamak için bir soybilimsel alan ontolojisinin oluşturulmasına odaklanmaktadır. Ayrıca önerilen çalışma ile akrabalık ilişkilerini listelerken aile, kişi, yer, zaman ve olay kavramları arasında anlamsal örüntülerin ortaya konulması düşünülmektedir. Bir ontolojinin en temel bileşeni şüphesiz ki hiyerarşik bir yapıda sunulan sınıflardır. Ontolojik yapılarda sınıflar aynı kategoriye ait kavramları bir arada tutmak için kullanılır. Sınıfların dışında sınıflar arasındaki ilişkiler ontolojiyi oluşturan temel elemanlar arasındadır. Nesne özelliği (Object Property) olarak da adlandırılan ilişkiler, ontolojinin sınıfları arasındaki bir tür etkileşimi temsil eder . Bir alan ontolojisinden bahsedildiğinde önemli başka bir kavram veri özellikleridir (Data Property). Veri özellikleri sınıfları tanımlamak için kullanılır. Bir sınıfa ait bir nesne özelliğinin türü, etiketi ve değeri vardır. Nesne özelliği, sınıflar arasında bağlantı kuran bir niteliği temsil ederken, data özelliği değişmez bir değere başvurur.

Ontoloji oluşturmak üzere kullanılan en yaygın dil kesinlikle The Web Ontology Language (OWL)'dir. OWL ontolojileri tanımlamak ve çeşitlemek için kullanılan ve World Wide Web (W3C) Consortium tarafindan geliştirilen bir anlamsal web dilidir. Fakat bu dillde kodlama yapmak bir editor olmadan oldukça zor olabilmektedir. Bu çalışma kapsamında soybilim ontolojisi için Cambridege Üniversitesi tarafindan tasarlanan ve araştırmacılar tarafindan sıklıkla kullanılan Protégé ontoloji oluşturma editörü kullanılmıştır. Protégé, kullanıcıların ontolojileri tanımlamaları için bir arayüz sağlayan ücretsiz bir açık kaynak çerçevesidir (Musen \& Team, 2015).

\subsection{Ontoloji Geliştirme Metodolojileri}

Belirli bir alana ait ontoloji geliştirilmesi dikkate alınması gereken, önemli ve dinamik bir süreçtir. Öncelikle ontolojisi oluşturulmak istenen alanın iyice anlaşılması gerekmektedir (Milli, Ünsal, \& Aktaş, 2016). Bu yüzden bir alan ontolojisi geliştirirken literatürde kabul görmüş bir ontoloji geliştirme metodolojisi kullanmak yapılan çalışmanın kullanılabilirliğini ve değerini önemli ölçüde arttıracaktır. Literatürde bir çok araştırmacının kullandığı kabul görmüş bazı ontoloji geliştirme metodolojileri mevcuttur. Skeletal Metodolojisi (Uschold \& Gruninger, 1996) ve 101 Metodolojisi (Noy \& McGuinness, 2001) literatürde kabul görmüş en çok kullanılan ontoloji geliştirme metodolojilerindendir. Önerilen çalışmada, ontoloji geliştirme metodolojisi olarak kullanım kolaylı̆̆ anlaşılması, uygulanabilirliği ve çoğu geliştirici ve araştırmacı tarafından genel kabul görmesi sebebiyle 101 metodolojisi seçilmiş̧ir. Bu metodoloji 7 temel adımdan oluşmaktadır. Metodolojinin bu temel adımları aşağıda verilmişsir;

\section{Ontolojinin alanının ve kapsamını belirlenmesi \\ 2. Mevcut ontolojileri yeniden değerlendirilmesi \\ 3. Ontolojideki önemli terimlerin listelenmesi}

91 I P a g e

www.iiste.org 
4. Sınıfların belirlenmesi ve sınıf hiyerarşisinin oluşturulması

5. Sınıfların nesne özelliklerinin ve veri özelliklerinin belirlenmesi

6. Veri türü ve nesne özelliklerinin kısıtlamalarını belirlenmesi

7. Sınıfların bireylerinin (örneklerinin) oluşturulması

\subsection{Soybilim Ontolojisinin Geliştirilmesi}

\subsubsection{Ontolojinin alanının ve kapsamını belirlenmesi}

Ontoloji oluşturma adımlarının her biri kendi içersinde ve genel olarak büyük önem arz etmektedir. Ontoloji geliştirme adımlarının herbirinin başarısı kendinden önce gelen adımların ne kadar sağlıklı yürütüldüğü ile doğrudan alakalıdır. Önerilen soybilim ontolojisini oluşturmak için kullanılan 101 metodolojisinin ilk adımında, geliştirilen uygulama kapsamlı bir şekilde tartışılmalıdır. İyi tanımlanmış bir ontoloji; (i) Ontolojinin çerçevesi nedir?, (ii) Kimler önerilen ontolojiden faydalancaktır?, (iii) Ontolojinin amacı nedir? gibi sorulara cevap vermelidir. Bunun yanında ontoloji geliștirme süreci ömür boyu devam edebilecek dinamik bir süreç olacağından önerilen ontolojinin kim tarafindan sürdürüleceğide bu aşamada karara bağlanmalıdır.

Önerilen soybilim ontolojisinin Türkçenin geniş akrabalık terimlerini içeren ve özellikle kalabalık geleneksel ailelere hitap edecek kapsamlı bir ontoloji olması planlanmaktadır. Soybilim ontolojisinin amacı son derece geniş akrabalık kavramlarının tek bir çatı altında toplanması sağlamaktır. Soybilim ontolojisinin bir başka amacı geleneksel soyağaçlarının ifade etmekte zorluk çektiği paralel akrabalık ilişkilerini detaylı bir şekilde görselleştirmesi olacaktır.

\subsubsection{Mevcut ontolojileri yeniden değerlendirilmesi}

Ontolojilerin en önemli özelliklerinden biri yeniden kullanılabilirliktir. Ontoloji oluşturma sürecine başlamadan önce bu alanda oluşturulan benzer ontolojiler literatürde araştırılmalı ve tartışılmalıdır. Akademik alanda aynı konuda yeni bir ontoloji geliştirmek yerine mevcut ontolojilerin geliştirilmesi daha faydalı olabilir. Ontolojilerin bir diğer özelliği de diğer ontolojilerle birleşebilmesidir. Sisteminizin diğer uygulamalarla etkileşime girmesi gerekiyorsa, bazen mevcut ontolojileri yeniden kullanmak bir gereklilik olabilir. Birçok ontoloji zaten elektronik ortamlarda ve uygun formatlarda mevcuttur ve onu değiştirmek veya genişletmek için ontoloji geliştirme ortamına aktarılabilir.

Önerilen çalışma kapsamında soybilim ontoloji oluşturmak için ikinci adım alana özgü daha önceden geliştirilmiş ontolojilerin tekrar gözden geçirilmesi olacaktır. Benzer ontolojilerin tekrar gözden geçirilmesi zaman ve maaliyet kaybını önlemek içindir. Ontoloji içersinde daha önceden hazırlanmış bazı bölümler olabilir. Hatta zaman zaman hazırlanmak istenilen ontolojinin tamamını bile bulmak mümkündür. Dolayısı ile daha önceden başka araştırmacılar tarafindan geliştirilmiş bir ontolojinin tekrar hazırlanması gereksizdir. Böyle bir durumda ontolojinin bir kısmının veya tamamının mevcut ontolojilerden içe aktarma yolu ile ontolojiye dahil edilmesi zaman ve maliyet açısından daha uygun olacaktır.

\subsubsection{Ontolojideki önemli terimlerin listelenmesi}

Ontoloji geliştirme süreçlerinin üçüncü adımı olan terimlerin listelenmesi aşamasında kullanılacak kavramların tamamından (sınıflar, nesne özellikleri, ilişkiler, veri özellikleri) ayrım gözetmeksizin ve sıralama kaygısı olmaksızın kapsamlı bir liste oluşturulmalıdır. Daha sonraki aşamalarda sınıflar, ilişkiler, veri özellikleri oluşturulurken ve sınıflar arasındaki hiyerarşi kurulurken bu kavramlar listesi göz önünde bulundurulacaktır. Önerilen soybilim ontolojisi için oluşturulan terim listesinin bir kısmı Tablo 1'de verilmiştir.

Ontoloji geliştirme süreci daha öncede söylendiği üzere dinamik bir süreçtir. Herhangi bir adımda unutulan bir durum da veya ontolojinin yeni gereksinimlerine göre güncellenmesi gerektiğinde ilgili adım tekrar gözden geçirilmelidir. Terimlerin belirlenmesi sürecinde de eksik kalan bazı terimler olabilir. Sınıflar ve özellikler belirlenirken bu eksiklik giderilebilir. 
Table 1: Soybilim ontolojisinin geliştirilme aşamasında kullanılması planlanan terim listesinden bir

$\begin{array}{llllllll}\text { No } & \text { Kavram } & \text { No } & \text { Kavram } & \text { No } & \text { Kavram } & \text { No } & \text { Kavram } \\ \mathbf{1} & \text { Baba } & 14 & \text { Amca } & 27 & \text { Kardeşidir } & 40 & \text { Telefon } \\ \mathbf{2} & \text { Anne } & 15 & \text { Emmi } & 28 & \text { Annesidir } & 41 & \text { Görümce } \\ \mathbf{3} & \text { Kardes } & 16 & \text { Hala } & 29 & \text { Babasidir } & 42 & \text { Elti } \\ \mathbf{4} & \text { Erkek_Kardes } & 17 & \text { Kuzen } & 30 & \text { Torunudur } & 43 & \text { Gelin } \\ \mathbf{5} & \text { Kiz_Kardes } & 18 & \text { Amca_Oglu } & 31 & \text { Baldiz } & 44 & \text { Damat } \\ \mathbf{6} & \text { Dogum_Tarihi } & 19 & \text { Amca_Kizi } & 32 & \text { Yenge } & 45 & \text { Yigenidir } \\ \mathbf{7} & \text { Anne_Anne } & 20 & \text { Dayi_Oglu } & 33 & \text { Göreceli_Akrabalik } & 46 & \text { Karisidr } \\ \mathbf{8} & \text { Baba_Anne } & 21 & \text { Dayi_Kizi } & 34 & \text { Dünür } & 47 & \text { Kocasidir } \\ \mathbf{9} & \text { Dede } & 22 & \text { Teyze_Oglu } & 35 & \text { Kaynana } & 48 & \text { Yengesidir } \\ \mathbf{1 0} & \text { Soyisim } & 23 & \text { Teyze_Kizi } & 36 & \text { Kayin_Baba } & 49 & \text { Adres } \\ \mathbf{1 1} & \text { Isim } & 24 & \text { Hala_Oglu } & 37 & \text { Kayin_Birader } & 50 & \text { Kiz_Kardesidir } \\ \mathbf{1 2} & \text { Dayi } & 25 & \text { Hala_Kizi } & 38 & \text { Bacanak } & 51 & \text { Kizidir } \\ \mathbf{1 3} & \text { Teyze } & 26 & \text { Mutlak_Akrabalik } & 39 & \text { Eniste } & 52 & \text { Damadidir }\end{array}$

\subsubsection{Sınıfların belirlenmesi ve sınıf hiyerarşisinin oluşturulması}

Herhangi bir alana ait ontolojinin can damarı sınıflardır. Bu yüzden sınıflar belirlenirken ve sınıf hiyerarşisi oluşturulurken dikkatli olunması gerekir. Çalışma kapsamında ontoloji oluşturulurken kullanılacak olan terim listesi ayrım gözetmeksizin oluşturulduktan sonra, bu liste içersinden hangilerinin sınıf olacaklarının belirlenmesi gerekmektedir. Sınıflar belirlenirken aralarındaki hiyerarşide göz önünde bulundurulmalıdır. Protégé ontoloji oluşturma editörü vasıtasıyla oluşturulan soybilim ontolojisinin sınıfları ve hiyerarşisi Şekil 1'de görülmektedir.

Her ontoljinin en süt sınıfı (root node) Thing sınıfıdır. Bir alan ontolojisinde oluşturulması planlanan tüm sınıflar bu sınıfın alt sınıfı olarak belirlenmelidir. Önerilen soybilim ontolojisinde Thing sınıfina ait iki adet alt sınıf bulunmaktadır. Bu alt sınıflardan ilki kan bağı yolu ile akrabalığı kasteden mutlak akrabalıktır. Bu akrabalık türü bireyin seçimi olmadığından ve doğuştan kan bağı üzerine olduğu için mutlak akrabalık diye isimlendirilmiştir. Proje kapsamında önerilen soybilim ontolojisinde Thing sınıfının bir diğer alt sınıfı evlilik bağı yolu ile akrabalığı kasteden göreceli akrabalıktır. Bu akrabalık türü bireyin kendi seçimi olduğundan ve duruma göre değişebileceğinden bu şekilde isimlendirilmesi uygun görülmüştür. Proje kapsamında oluşturulan diğer sınıflar uygun olan kök düğüm altına yerleştirilrmiştir.

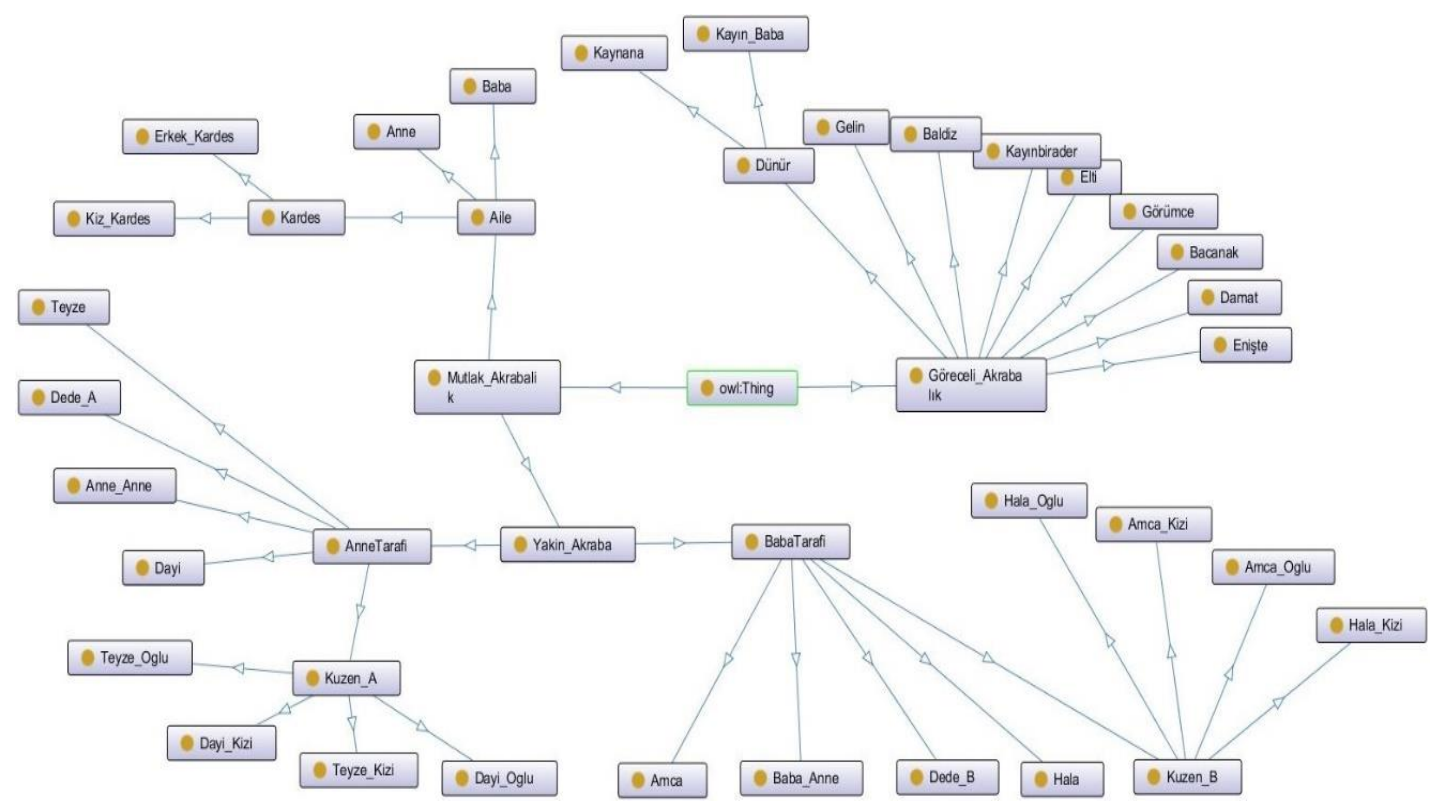

Şekil 1. Önerilen soybilim ontolojisinin sınıfları ve aralarındaki hiyerarşik yapının Protégé editöründe gösterilmesi

93 | P a g e

www.iiste.org 


\subsubsection{Sinıfların nesne özelliklerinin ve veri özelliklerinin belirlenmesi}

Yalnızca sınıfları ve aralarındaki hiyerarşik yapıyı belirlemek, kullanıcılara verilecek bilgileri net bir şekilde göstermek için yeterli değildir. Ontoloji geliştirme adımlarının beşincisi nesne ve veri özelliklerinin belirlenmesi aşamasıdır. Bu aşamada daha önceden belirlenen terim listesi içersinden hangi kavramların nesne özelliği hangi kavramların veri özelliği olduğu ayrımı yapılmaktadır. Proje kapsamında oluşturulan soybilim ontolojisinde kullanılan bazı nesne özellikleri ve veri özellikleri Şekil-2'de gösterilmektedir.

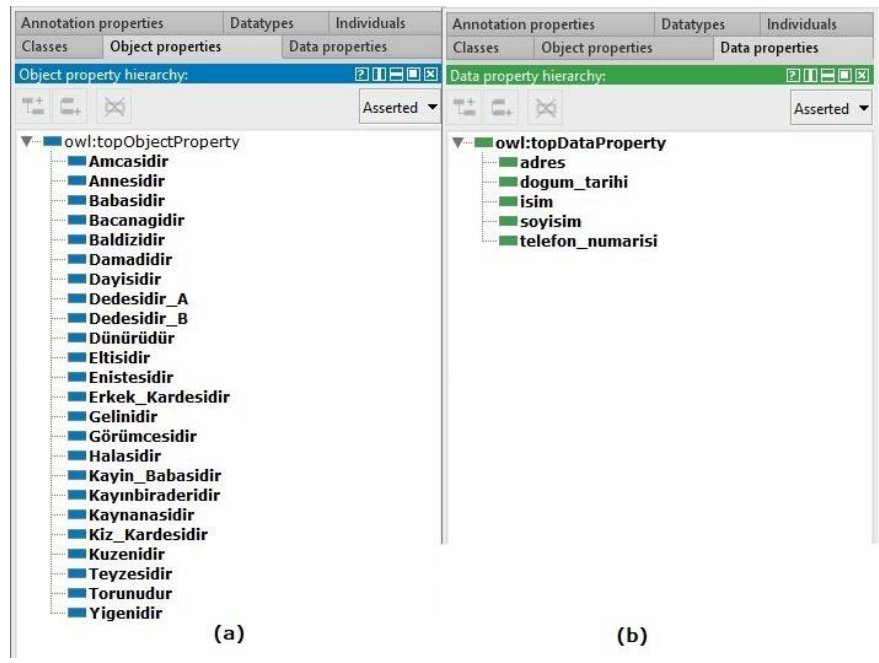

Şekil 2. Önerilen soybilim ontolojisinin nesne ve veri özelliklerinin Protégé editöründe gösterilmesi

Ontolojiler Özne (Subject), Nesne (Object) ve Yüklemden (Predicate) oluşan üçlü cümlelerden meydana gelir. Bu üçlülerde kavramlar (sınıflar) arasındaki bağlantılar (ilişkiler) Nesne Özellikleri ile gösterilmektedir. Örneğin 'Kayınbirader' 'Gelinin' 'Erkek Kardeşidir' ontoloji üçlüsü bize kayınbirader ile gelin arasındaki ilişki tanımlamaktadır. Burada 'Kayınbirader' Özne, 'Gelin' Nesne olarak ontoloji üçlüsünde yer almaktadır. Bu iki sınıf arasındakiyi ilişkiyi belirten Yüklem ise 'Erkek Kardeşidir' kavramı cümlede Nesne Özelliği görevinde bulunmaktadır. Veri özellikleri, sınıfların veri niteliklerini atayarak sınıflara ait bireyleri (individual) tanımlamak için kullanılır. Terimlerin listelenmesi adımında oluşturulan kavramlar listesinde isim, soyisim adres gibi terimler veri özellikleridir ve sınıflara ait bireylerin tanımlanması için kullanılacaklardır.

\subsubsection{Veri türü ve nesne özelliklerinin kısıtlamalarını belirlenmesi}

Alana özgü ontoloji geliştirilmesi aşamalarından altıncısı veri türlerinin ve kısıtlamaların belirlenmesi aşamasıdır. Sınıflara ait bireyleri niteleyen veri özellikleri mutlaka bir formatta olması gerekmektedir. Şekil-2'de görüldügüü üzere önerilen soybilimsel ontolojide bireyleri niteleyen 5 veri özelliği mevcuttur. Bunlardan sadece 'dogum_tarihi' veri özelliğinin veri türü DateTime olarak atanmıştır. Diğer veri özelliklerinin türü string olarak belirlenmiştir. Çalışma kapsamında soybilimsel ontoloji geliştirilirken herhangi bir kısıtlama (restriction) düşünülmemiştir. Fakat ontolojiler modüler yapıya sahip dinamik süreçlerdir. Herhangi bir nesne özelliği için bir kısıtlamaya gereksinim duyulduğunda ontoloji çerçevesine sonradan eklenmesi düşünülmektedir.

\subsubsection{Sınıfların bireylerinin (örneklerinin) olușturulması}

101 ontoloji geliştirme metodoloisinin son adımı daha önceki adımlarda tanımlanmış olan sınıflara ait bireylerin (individual) oluşturulmasıdır. Önerilen soybilim ontolojisinde sınıfların bireyleri gerçek kişileri referans etmektedir. Bir kişi soyağacında aynı anda birden fazla karaktere sahip olabileceğinden birden fazla sınıfında üyesi olabilir. Örneğin soybilim ağacında tek bir kişi hem amca, hem baba, hem erkek kardeş ve daha fazla ünvana sahip olabilmektedir. Dolayısı ile bu kişi ne kadar fazla karaktere sahip ise ait olduğu sınıflara birey olarak eklenmelidir. Öenerilwn soybilim ontolojisinde bir bireyin farklı akrabalık bağlarını gösteren bir örnek Şekil 3’te gösterilmektedir. 


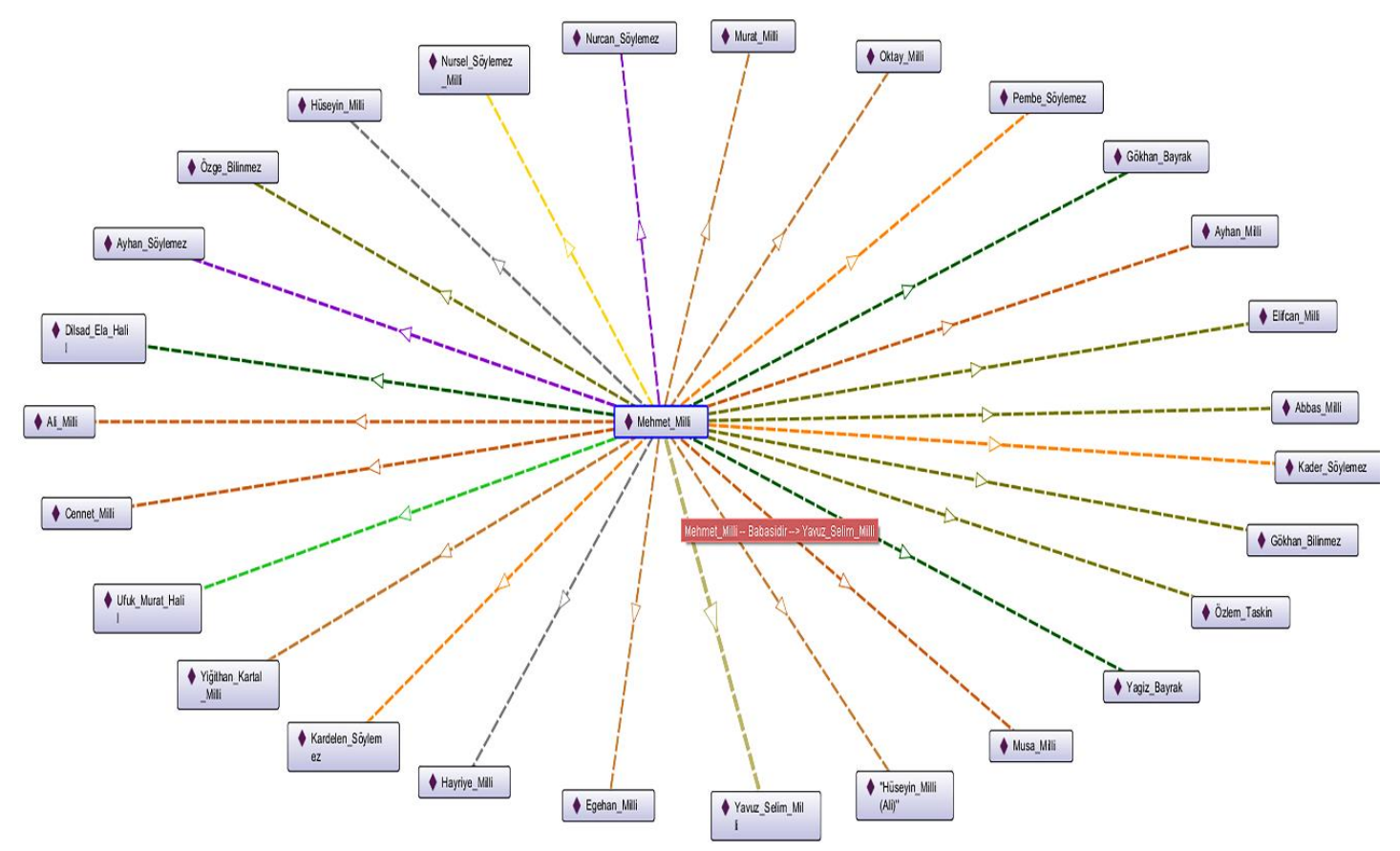

Şekil 3. Önerilen soybilim ontolojisinin bir bireyin ilişkilerini gösteren temsili bir örnek

\section{Sonuç ve Gelecek Çalışmalar}

Günümüzde, nüfus müdürlüklerinde, kütüphanelerde veya diğer resmi daireleride vatandaşların soyağacı bilgileri metin biçimsel bilgiler dahilinde tutulmaktadır. Soyağaçlarının metin biçimsel gösterimlerinin insanlar tarafindan anlaşılması ve yorumlanması zor olabimektedir. Bu yüzden soyağaçlarının görselleştirlmesi soyağacı bilgilerinin insan gözüyle daha iyi anlaşılması sağlarken akrabalık ilişklerini daha açık bir şekilde ortaya koyacağı kesindir. Fakat mevcut sistemler akrabalık bağlarını gerekli altyapı kaynaklarının olmaması sebebiyle ancak hiyerarşik bir yapıda sunabilirler. Oluşturulan soyağacı pararlel ilişkiler kurmaktan yoksundur. Tüm bunların yanında hali hazırda mevcut soy kütükleri akrabalık ilişkilerini listelerken aile, kişi, yer, zaman ve olay kavramları arasında anlamsal örüntüleri ortaya koymakta yetersiz kalmaktadır.

Mevcut soyağacı sistemlerinin tüm bu yukarıda bahsedilen eksiklerinin giderilmesi için, önerilen çalışmada soyağacı verilerinin daha anlamlı temsil edilmesi ve yazılım ajanları tarafından da yorumlanabilmesi için ortak bir çerçeve yaratılmışıı. Soyağacı bilgileirnin temsil edildiği ortak kelimeler listelenmiş ve aralarında bazı hiyerarşik sınıflar kurulmuştur. Böylelikle soyağacı verilerinin yeniden kullanılabirliği ve platformlar arasında ortak paylaşımı sağlanmıştır.

Tüm bunların yanında milletler arası kültürel farklılıkların olması, akraba ilişkilerinin farklı terimler ile ifade edilmesi ortak bir soyağacı tanımlamalarını gerektirmktedir. Çalışma kapsamında geliştirilen soybilim ontolojisinin daha geniş kapsamda kullanılabilmesi için upper seviye ontolojiler ile hizalanması şarttır. Gelecek çalışmalarda geliştirilen soybilim ontolojisinin daha geniş kapsamda kullanılması ve milletler arası bir temsil gücünün olması için upper seviye bir ontoloji ile hizalanması düşünülmektedir.

\section{Referanslar}

Accenture. (2015). Accenture Dijitalleşme Endeksi Türkiye Sonuçları. İstanbul.

Gangemi, A., Guarino, N., Masolo, C., Oltramari, A., \& Schneider, L. (2002). Sweetening Ontologies with DOLCE. In A. Gómez-Pérez \& V. R. Benjamins (Eds.), Knowledge Engineering and Knowledge Management: Ontologies and the Semantic Web (pp. 166-181). Berlin, Heidelberg: Springer Berlin Heidelberg.

Gruber, T. R. (1993). A translation approach to portable ontology specifications. Knowledge Acquisition, 5(2), 199-220. https://doi.org/10.1006/knac.1993.1008

95 I P a g e 
Gruber, T. R. (1995). Toward principles for the design of ontologies used for knowledge sharing? International Journal of Human-Computer Studies. https://doi.org/10.1006/ijhc.1995.1081

Kazan, H. (2017). Digital Magazine With Its Advantages and Disadvantages. The Turkish Online Journal of Design, Art and Communication, 7(1), 17-24. https://doi.org/10.7456/10701100/002

Kuraoka, K., \& Batres, R. (2003). An Ontological Approach to Represent HAZOP Information, (April).

Maedche, A., \& Staab, S. (2000). Semi-Automatic Engineering of Ontologies from Text. In Proceedings of the 12th Internal Conference on Software and Knowledge Engineering (pp. 231239). https://doi.org/10.1.1.41.2894

Milli, M. (2021). Creating Intelligent Management System for Turkey on Ontological Sensor Data. Dokuz Eylül University.

Milli, M., Ünsal, E., \& Aktaş, Ö. (2016). Creating Ontology Based Concept Maps Which Can Be Queried in Computer Enviroment. Tojsat, 6(2), 30-37.

Musen, M. A., \& Team, P. (2015). The protégé project. AI Matters, 1(4), 4-12. https://doi.org/10.1145/2757001.2757003

Noy, N., \& McGuinness, D. (2001). Ontology development 101: A guide to creating your first ontology. Development, 32, 1-25. https://doi.org/10.1016/j.artmed.2004.01.014

Tan, M. T., \& Hashim, R. (2019). A Process for Building a Consistent Ontology for Family. Lecture Notes in Electrical Engineering, 520, 467-475. https://doi.org/10.1007/978-981-13-1799-6_49

Terziev, I., Kiryakov, A., \& Manov, D. (2003). Base upper-level ontology (BULO) Guidance.

Uschold, M., \& Gruninger, M. (1996). Ontologies: principles, methods and applications. The Knowledge Engineering Review, 11(02), 93. https://doi.org/10.1017/S0269888900007797

Xia, C.-J., Liu, W., Zhang, L. and Zhu, W.-J. (2014). A Genealogical Ontology in the Form of BIBFRAME Model. Library Tribune, 34(11), 5-19. 